\title{
Let-7c inhibits migration and epithelial-mesenchymal transition in head and neck squamous cell carcinoma by targeting IGF1R and HMGA2
}

\author{
Bo Hou ${ }^{1,2}$, Hajime Ishinaga ${ }^{1}$, Kaoru Midorikawa², Satoshi Nakamura1, Yusuke \\ Hiraku ${ }^{2}$, Shinji Oikawa ${ }^{2}$, Ning $\mathrm{Ma}^{3}$, Kazuhiko Takeuchi ${ }^{1}$ and Mariko Murata ${ }^{2}$ \\ ${ }^{1}$ Department of Otolaryngology-Head and Neck Surgery, Graduate School of Medicine, Mie University, Tsu, Mie 514-8507, \\ Japan \\ ${ }^{2}$ Department of Environmental and Molecular Medicine, Graduate School of Medicine, Mie University, Tsu, Mie 514-8507, \\ Japan \\ ${ }^{3}$ Graduate School of Health Science, Suzuka University of Medical Science, Suzuka, Mie 513-8670, Japan \\ Correspondence to: Kazuhiko Takeuchi, email: kazuhiko@clin.medic.mie-u.ac.jp \\ Mariko Murata, email: mmurata@doc.medic.mie-u.ac.jp
}

Keywords: Let-7C; IGFIR; HMGA2; epithelial-mesenchymal transition; head and neck squamous cell carcinoma

Received: May 02, $2017 \quad$ Accepted: December 27, $2017 \quad$ Published: January 02, 2018

Copyright: Hou et al. This is an open-access article distributed under the terms of the Creative Commons Attribution License 3.0 (CC BY 3.0), which permits unrestricted use, distribution, and reproduction in any medium, provided the original author and source are credited.

\section{ABSTRACT}

To elucidate the molecular mechanisms underlying the progression of head and neck squamous cell carcinoma (HNSCC), we investigated the function of let7c as a tumor suppressor. Let-7c expression was significantly down-regulated in HNSCC tumor tissues and cell lines. In vitro and in vivo studies revealed that let-7c negatively regulated HNSCC proliferation, migration and epithelial-mesenchymal transition (EMT). To explore the underlying mechanisms that affect these molecular events achieved by let-7c, we predicted its target genes. We performed luciferase assay and confirmed that insulin-like growth factor 1 receptor (IGF1R) and high mobility group AT-hook 2 (HMGA2) were the direct targets of let-7c. Knocking down of IGF1R and HMGA2 inhibited HNSCC progression, including proliferation, migration and EMT in HNSCC cells. Re-expression of these genes overcame let-7c-mediated inhibition. Taken together, our finding suggests that let-7c inhibits HNSCC progression by targeting IGF1R and HMGA2 and might be a novel target for HNSCC treatment.

\section{INTRODUCTION}

Head and neck cancer is one of the most common types of human cancer, with nearly 690,000 new cases and 380,000 deaths occurring each year [1]. Approximately $90 \%$ of these tumors are head and neck squamous cell carcinoma (HNSCC) [2]. The therapy for HNSCC usually includes surgery with or without concurrent chemotherapy and radiation therapy, or radiation alone. Despite the use of advanced surgical techniques and effective chemotherapeutic agents, the overall survival of patients with HNSCC has remained unchanged, with a 5 -year survival rate of about 50\% [3]. Metastasis accounts for the majority of deaths of patients with HNSCC [4]. To date, the molecular mechanisms that promote HNSCC proliferation and migration are largely unknown. There is an urgent need to identify target molecules for novel therapeutic strategies.

MicroRNAs (miRNAs) are small non-coding RNAs that play an important regulatory role in cancer development and progression [5]. MiRNAs usually contribute to the regulation of their target genes' mRNA by base-pairing to the 3 '-untranslated region (3'-UTR), which results in either mRNA degradation or translational inhibition. It has been reported that a given miRNA can bind to mRNAs derived from hundreds of different genes [6], and it is therefore estimated that more than $30 \%$ of all protein-coding genes within the human genome are targeted by miRNAs [7]. MiRNAs can act either as oncogenes or tumor suppressors depending on the 
function of their target molecules and on the regulation of downstream signaling pathways [8].

The let-7 family of miRNAs is widely viewed as playing a role in tumor suppression. Humans have 10 mature let-7 family sequences (let-7a, 7b, 7c, 7d, 7e, 7f, $7 \mathrm{~g}, 7 \mathrm{i}, \mathrm{miR}-98$, and miR-202). To predict which miRNA in the let-7 family is most important in terms of HNSCC progression, we first checked their expressions in HNSCC using starBase v2.0. The database generated by 37 independent studies [9] showed that let-7c was the most down-regulated miRNA (fold change $=0.236, P=0.0000$ ) in HNSCC compared to normal tissues among the 10 mature let-7 family members (let-7a, fold change $=0.760$, $P=0.0002$; let-7b, fold change $=0.847, P=0.0311$; let$7 \mathrm{~d}$, fold change $=1.388, P=0.0000$; let- $7 \mathrm{e}$, fold change $=1.087, P=0.3605$; let-7f, fold change $=0.774, P=$ 0.0118 ; let-7g, fold change $=0.858, P=0.0226$; let-7i, fold change $=1.230, P=0.0005$; miR-98, fold change $=1.0420, P=0.5318 ;$ miR-202, fold change $=0.957$, $P=0.0041$ ). In our previous study, let-7c miRNA was demonstrated to be the only let-7 family member which showed significant difference between four paired HNSCC tissues and adjacent non-tumor tissues as determined by miRNA microarray and it was confirmed to be downregulated in sixteen HNSCC tissues by quantitative realtime PCR (RT-qPCR) [10]. However, the exact role of let$7 \mathrm{c}$ underlying $\mathrm{HNSCC}$ progression remains unclear.

Online bioinformatics tools indicate that let-7c has a conserved binding site in the 3'-UTRs of many genes, including insulin-like growth factor 1 receptor $(I G F 1 R)$, high mobility group AT-hook 2 (HMGA2) and others. $I G F I R$ and $H M G A 2$ are important factors that are involved in cancer progression. In clinical settings, up-regulation of either IGF1R or HMGA2 protein has been reported to be strongly linked to poor prognosis in malignancies such as gastric cancer and breast cancer [11, 12]. More strikingly, IGFIR and HMGA2 are well documented as attractive targets for anti-cancer treatment $[13,14]$. Recent studies have reported that overexpression of IGFIR [15] and $H M G A 2$ [16] enhances tumor growth and migration in prostate cancer and colorectal cancer, respectively. In addition, IGF1R and HMGA2 play an essential role in inducing epithelial-mesenchymal transition (EMT) in cancers $[17,18]$. No reports have clarified the relation between let-7c and its potential targets, IGFIR and $H M G A 2$, and the underlying mechanism of action of let7c. Therefore, for the first time, we proposed and tested the hypothesis that let-7c inhibits tumor cell growth, migration, and EMT by directly targeting IGFIR and $H M G A 2$. Our findings identified let-7c as a tumor suppressor miRNA and provided new insights into the molecular function of let-7c and its target genes $I G F 1 R$ and $H M G A 2$, suggesting new therapeutic targets in HNSCC.

\section{RESULTS}

\section{Let-7c directly targets IGF1R and HMGA2 by binding to their $3^{\prime}$-UTRs}

In our previous study, we found that let-7c expression was significantly decreased in HNSCC tissues compared to adjacent non-tumor tissues [10]. Predicting the target genes of let- $7 \mathrm{c}$ was based on TargetScan Human online database (Release 7.0: August 2015, http://www. targetscan.org/). Let-7c has potential binding sites at the 3'-UTRs of IGFIR and HMGA2 mRNAs. Measurement of IGF1R and HMGA2 protein levels in 15 HNSCC tumor tissues and adjacent non-tumor tissues showed significantly higher levels of both proteins in the HNSCC tumor tissues than in the non-tumor tissues (Figure 1A). Furthermore, we confirmed up-regulation of both proteins in HNSCC by immunohistochemistry (IHC). Positive membrane staining of IGF1R and positive nuclear staining of HMGA2 were observed in tumor tissues, with no or weak immunoreactivity of these proteins in adjacent non-tumor tissues (Figure 1B). These results indicate that IGFIR and HMGA2 might be involved in HNSCC carcinogenesis through let-7c downregulation.

In addition, we confirmed that the expression levels of let-7c in HNSCC cell lines SAS, Ca9-22, and H0-1-u-1 were significantly lower than in non-malignant nasopharyngeal epithelial cell line NP69 (Figure 1C). Furthermore, IGFIR and HMGA2 were significantly upregulated in HNSCC cell lines SAS, Ca9-22, and H0-1-u-1 compared to non-malignant cell line NP69 (Figure 1D, 1E). In order to confirm that the $3^{\prime}-\mathrm{UTR}$ of the IGFIR and $H M G A 2$ mRNAs were indeed targeted by let-7c, we fused the sequences of the wild-type $3^{\prime}$-UTRs of IGFIR and HMGA2 mRNAs, as well as mutated sequences of these genes (Figure $1 \mathrm{~F}$ and $1 \mathrm{G}$ ) that disrupt complementary binding of let-7c, downstream of a luciferase reporter gene. All four luciferase constructs were transfected into cells that were also co-transfected with either negative-miRNA control or let-7c. As measured by luciferase assays, the activity of the wild-type IGFIR luciferase construct was significantly reduced by let- $7 \mathrm{c}$ compared to control, whereas the activity of the mutant $I G F 1 R$ construct was unaffected (Figure 1F). These results indicate that the 3'UTR of IGFIR mRNA can be complemented and targeted by let-7c. Similar results were obtained in the case of $H M G A 2$ (Figure 1G). These findings showed that IGF1R and $H M G A 2$ mRNA were direct targets of let-7c.

\section{Let-7c inhibits IGF1R and HMGA2 expression in HNSCC cell lines}

Having identified IGFIR and HMGA2 as targets of let-7c, we next investigated the role of let-7c in two HNSCC cell lines SAS and Ca9-22. Using the pCMVMIR-let-7c vector, we established corresponding cell lines, 

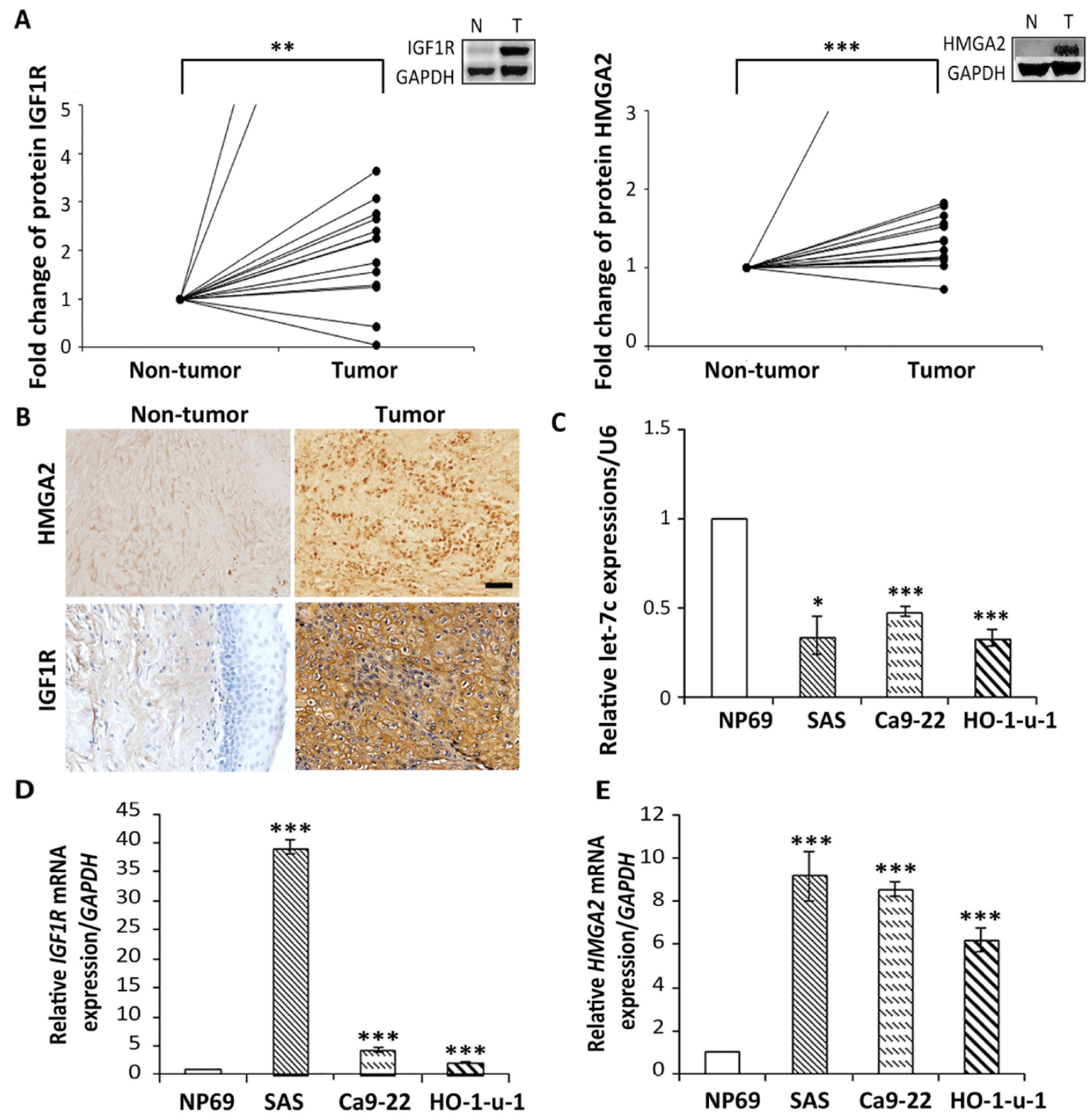

F

C
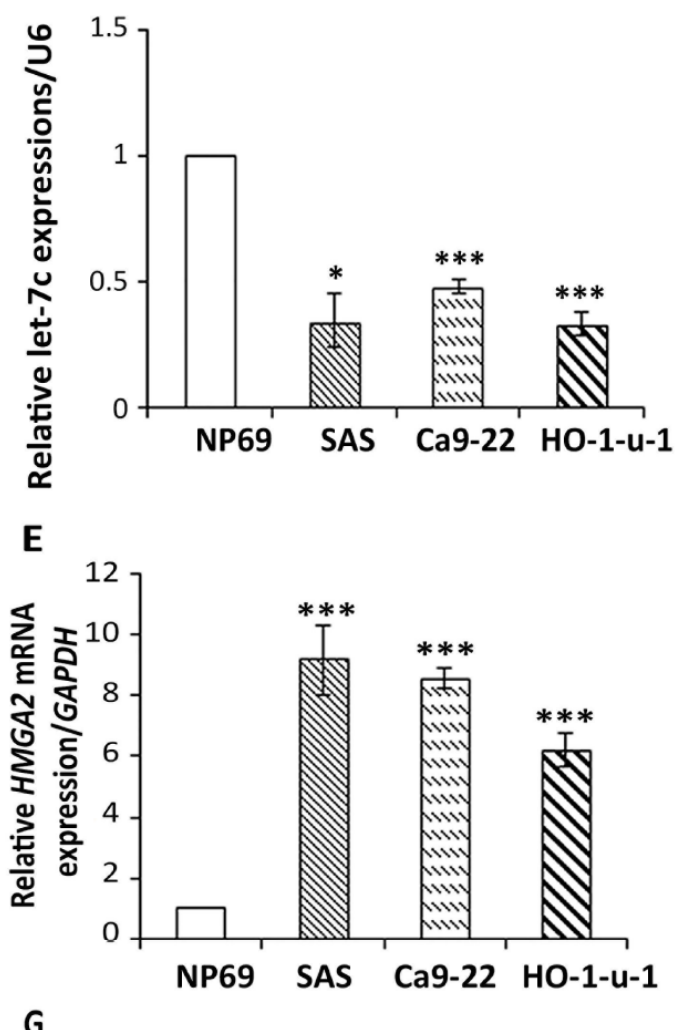

\begin{tabular}{|ccc}
$\begin{array}{c}\text { WT IGF1R 3'-UTR } \\
\text { 5' }\end{array}$ & ...CCCCAAACAUUUA-U-CUACCUCAU \\
Let-7c & UUGGUAUGUUGGAUGAUGGAGU \\
MT IGF1R 3'-UTR & $5^{\prime}$ & ...CCCCCAAACAUUUAUGAUGGAGUU \\
\hline
\end{tabular}
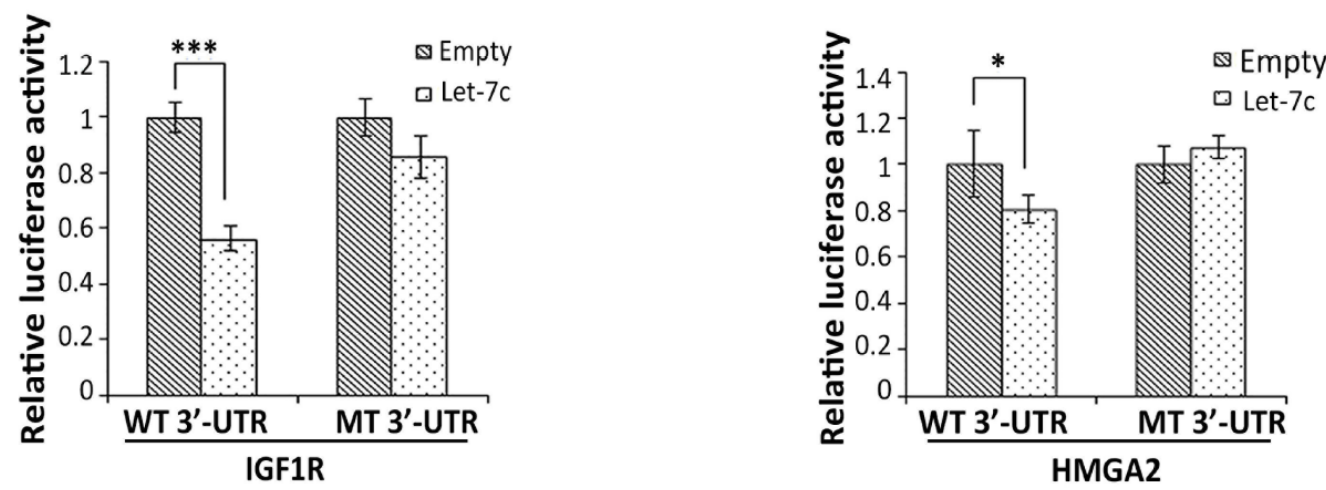
Figure 1: Let-7c directly binds to the $3^{\prime}$-UTRs of IGF1R and HMGA2. Relative protein levels of (A) IGF1R and HMGA2. IGF1R and HMGA2 in HNSCC tumor tissues and adjacent non-tumor tissues $(n=15)$ were examined by western blot analysis with GAPDH serving as loading control. Thereafter, the target protein levels were calculated as fold change compared to paired non-tumor levels. Non-tumor levels were set as 1. Statistical analysis was performed using the Student's paired $t$-test. (B) Representative IHC staining of IGF1R and HMGA2 in HNSCC tumor tissues and adjacent non-tumor tissues. Original magnification $\times 100$ and $\times 200$; bar represents $50 \mu \mathrm{m}$. Expression of (C) Let-7c, (D) IGF1R, and (E) HMGA2 in HNSCC cell lines SAS, Ca9-22, and H0-1-u-1 compared to nonmalignant nasopharyngeal epithelial cell line NP69. Let-7c-binding sites in the IGF1R and HMGA2 3'-UTRs were predicted by TargetScan. (F) 2619-2626nt of the IGF1R 3'-UTR sequence and (G) 21-28nt of the HMGA2 3'-UTR sequence, as well as the complementary let-7c binding sequences and the target mutated sequences, are shown in the boxed rectangles. For the luciferase reporter assays, SAS cells were co-transfected with $50 \mathrm{ng}$ of PCMV-MIR vector or PCMV-MIR-let-7c vector and $100 \mathrm{ng}$ dual-luciferase vector containing either wild-type or mutant 3'-UTR of (F) IGF1R and (G) HMGA2. The relative firefly luciferase activity normalized with renilla luciferase was measured $24 \mathrm{~h}$ after transfection. Statistical analysis was performed using the Student's $t$-test. ${ }^{*} P<0.05 ;{ }^{* *} P<0.01 ;{ }^{* * *} P<0.001$.

SAS-let-7c and Ca9-22-let-7c, which stably expressed let7c (Figure 2A, 2B), and examined the effect of let-7c on the expression of $I G F 1 R$ and $H M G A 2$. Overexpression of let-7c through stable transduction significantly reduced mRNA levels of IGF1R and HMGA2 compared with the empty control in SAS and Ca9-22 cell lines (Figure 2C, 2D). Next, using western blotting with antibodies against IGF1R and HMGA2, we found that the levels of both proteins were also reduced in let-7c-expressing cells compared to the empty control (Figure 2E, 2F). We also determined the levels of IGF1R and HMGA2 proteins in let-7c-expressing SAS cells using immunocytochemistry (ICC), showing that let-7c significantly decreased the levels of both proteins (Supplementary Figure 1A, 1B). Of note, even transient transfection with a let-7c mimic was still sufficient to significantly elevate let-7c levels (Supplementary Figure 2A, 2B) and repress the expression of let-7c target genes, IGF1R and HMGA2 (Supplementary Figure 2C, 2D), in SAS cells and Ca9-22 cells. These data suggest that $I G F 1 R$ and $H M G A 2$ are repressed by let-7c in HNSCC cell lines.

\section{Let-7c inhibits colony formation, proliferation and migration in HNSCC cell lines}

Since IGF1R [19] and HMGA2 [18] were reported to promote tumorigenesis of HNSCC, we speculated that downregulation of their expression by let-7c should inhibit colony formation, proliferation, and migration of HNSCC cell lines. To validate this hypothesis, we first conducted colony formation assays in SAS and Ca9-22 cell lines. As illustrated in Figure $3 \mathrm{~A}$ and Figure 3B, the colony number of let-7c-expressing cells was significantly smaller than that of control cells. Next, we compared the rate of cell proliferation in these two HNSCC cell lines during a 3-day incubation, and found that let-7c significantly reduced cell growth compared to the control (Figure 3C, 3D). In addition, HNSCC cells transfected with let-7c exhibited a significant defect in cell migration compared to the control (Figure 3E). To investigate whether let-7c exerted its effects by regulating IGFIR and $H M G A 2$ in HNSCC cells, we re-expressed the coding region sequence of $I G F 1 R$ or $H M G A 2$ in let-7c stably transfected SAS cells (SAS-let-7c) using the pCMV6-IGF1R or pCMV6HMGA2 plasmid, respectively. Overexpression of $I G F 1 R$ and $H M G A 2$ promoted SAS-let-7c stable cell growth and migration (Figure 3F, 3G). Taken together, these results suggest that let-7c inhibits colony formation, cell proliferation, and migration in HNSCC cell lines and that re-expression of IGF1R or HMGA2 overcomes let-7cinhibited cell proliferation and migration.

\section{Let-7c inhibits EMT in HNSCC cell lines}

Tumor cell migration is often associated with the EMT process $[20,21]$. In addition, let-7c was shown to be related to EMT in non-small cell lung cancer patients [22]. We thus investigated the effects of let-7c on the EMT process in HNSCC. We examined two EMT-related molecules (E-cadherin, an epithelial marker; vimentin, a mesenchymal marker) using let-7c-expressing HNSCC cell lines. RT-qPCR revealed that the expression levels of CDH1 were significantly higher and those of VIM were significantly lower in let-7c-expressing HNSCC cells than the control groups (SAS cells in Figure 4A, Ca9-22 cells in Figure 4B). Western blotting showed the same pattern in the protein levels of E-cadherin and vimentin in both cell lines (Figure 4C, 4D). ICC showed that let-7c overexpression significantly increased E-cadherin protein levels and decreased vimentin protein levels in SAS cells (Supplementary Figure 3A, 3B). In addition, SAS-empty cells were spindle-shaped mesenchymal cells, whereas SAS-let-7c cells were rounded cells with epithelial phenotypes (Supplementary Figure 3C). These data suggest that let-7c inhibits the EMT process in HNSCC cell lines.

\section{Let-7c inhibits tumor growth and infiltration in vivo}

We next aimed to investigate whether let-7c had the same properties in vivo. We performed a xenograft study in which let-7c-transfected SAS cells were transplanted into the flanks of BALB/c athymic nu/nu mice $(n=8)$. As illustrated in Figure 5A, tumor growth in mice injected with let-7c-expressing SAS cells was markedly slowed compared to that in mice that received control miRNAexpressing cells. The mice were sacrificed for the evaluation of tumor formation 17 days after inoculation (Figure 5B). The tumor weight of SAS xenografts was 
significantly lower in let-7c-expressing tumors than in control tumors (Figure 5C). The tumor xenograft experiment indicates that let-7c plays a role in suppressing HNSCC tumorigenicity.

Tumor sections were stained with H\&E to visualize the morphology of the xenograft tumors. As shown in Figure 5D, tumor cells in the control group infiltrated the adipose layer of the skin around the tumor, indicating greater aggressiveness than let-7c-expressing tumors. Moreover, the number of blood vessels (Figure 5D, arrows) inside the tumor nest was much higher in the control group than in the let-7c group, indicating that let- 7c inhibited infiltration of tumor cells at the invasive front in vivo.

To confirm that let-7c could modulate EMT phenotype in vivo, we investigated the protein levels of IGF1R, HMGA2, E-cadherin, and vimentin by IHC. The staining intensities of IGF1R and HMGA2 were much lower in let-7c-expressing SAS cells compared to the control. Higher levels E-cadherin and lower levels of vimentin were observed in let-7c-expressing SAS cells (Figure 5E). These results show that let-7c inhibits IGF1R and HMGA2 expression levels and reverses EMT in vivo.
A

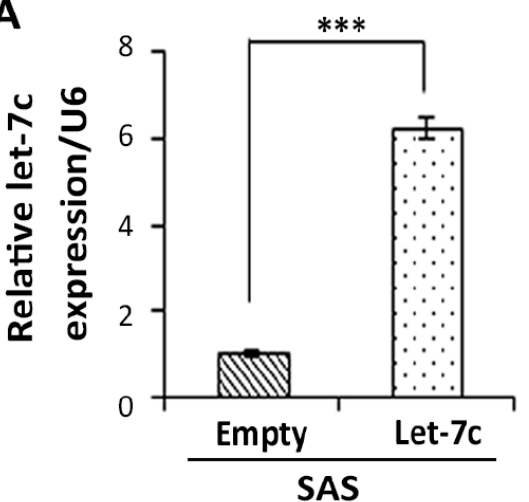

C

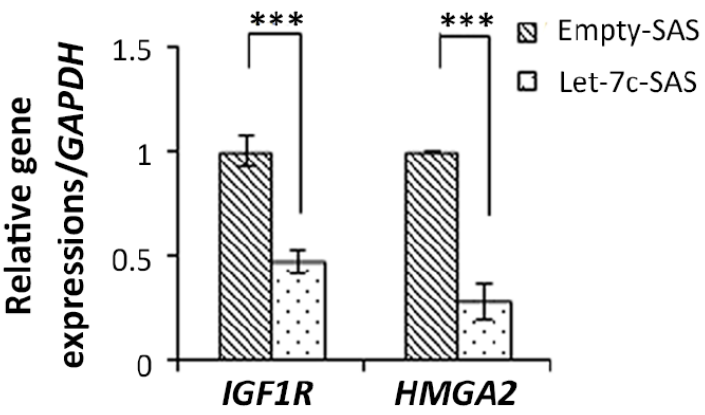

$\mathbf{E}$

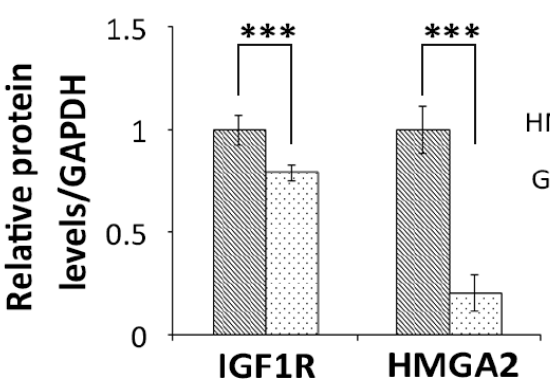

B

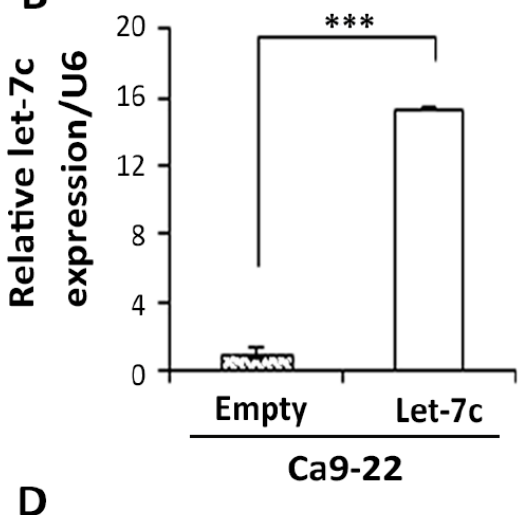

D

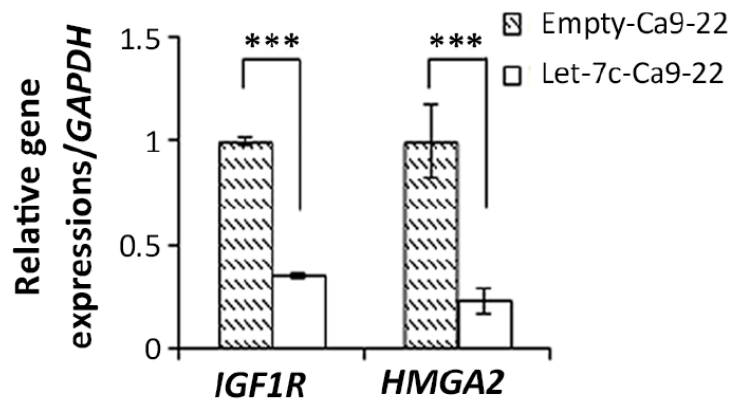

$\mathbf{F}$

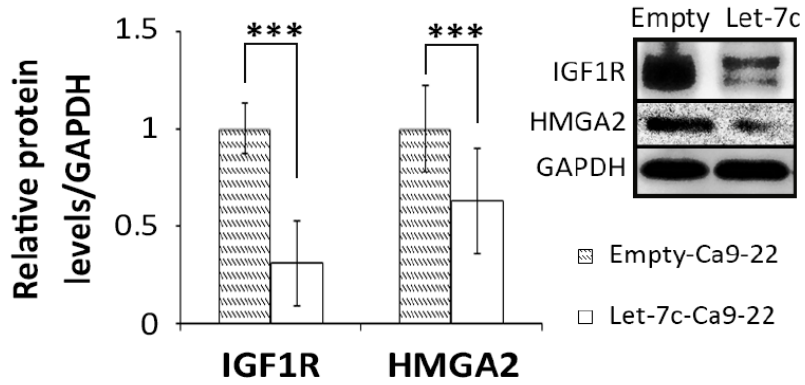

Figure 2: Let-7c inhibits IGF1R and HMGA2 expression in HNSCC cell lines. HNSCC cells were stably transfected with either pCMV-MIR vector or pCMV-MIR-let-7c vector. Expression levels of (A, B) let-7c and (C, D) IGF1R and HMGA2 mRNA were examined in HNSCC cell lines SAS and Ca9-22, respectively, with RT-qPCR. (E, F) IGF1R and HMGA2 protein levels were examined by western blot analysis in stably transfected let-7-expressing SAS and Ca9-22 cell lines, respectively, with GAPDH serving as loading control. $P$-values were calculated using the Student's $t$-test. ${ }^{* * *} P<0.001$. 
A

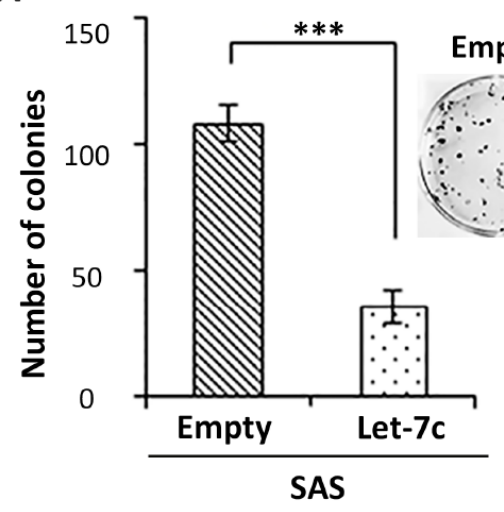

C

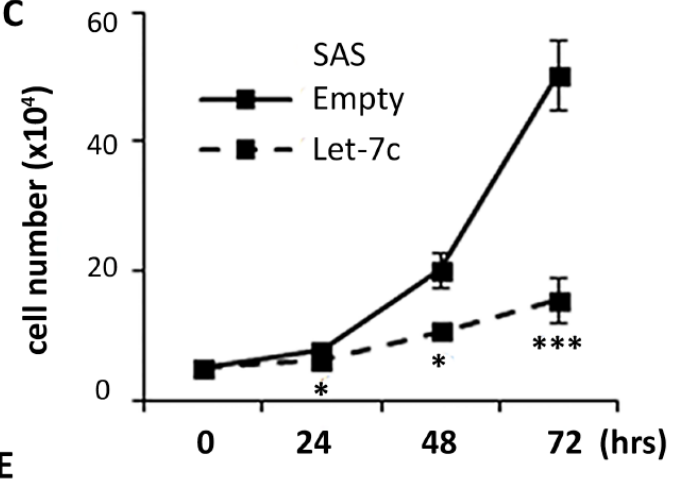

B

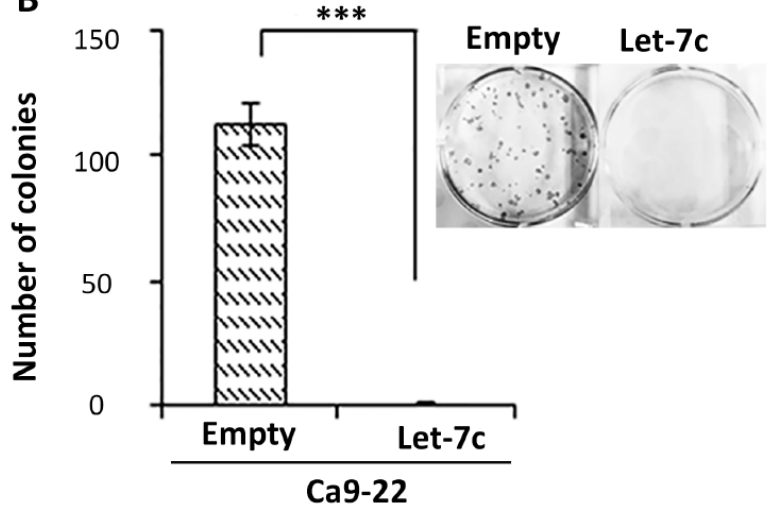

D

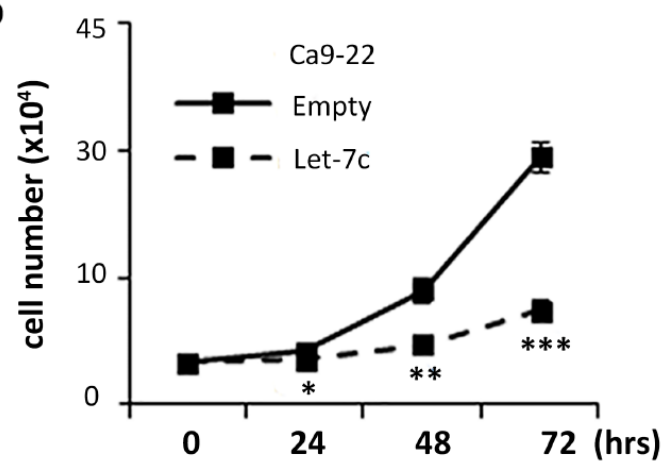

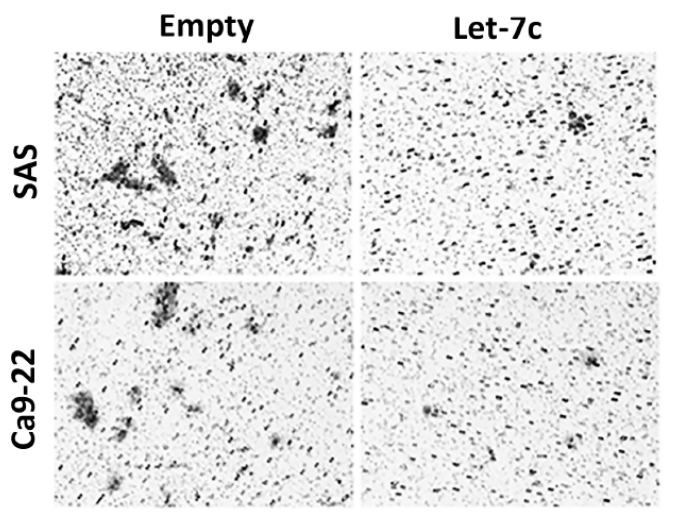
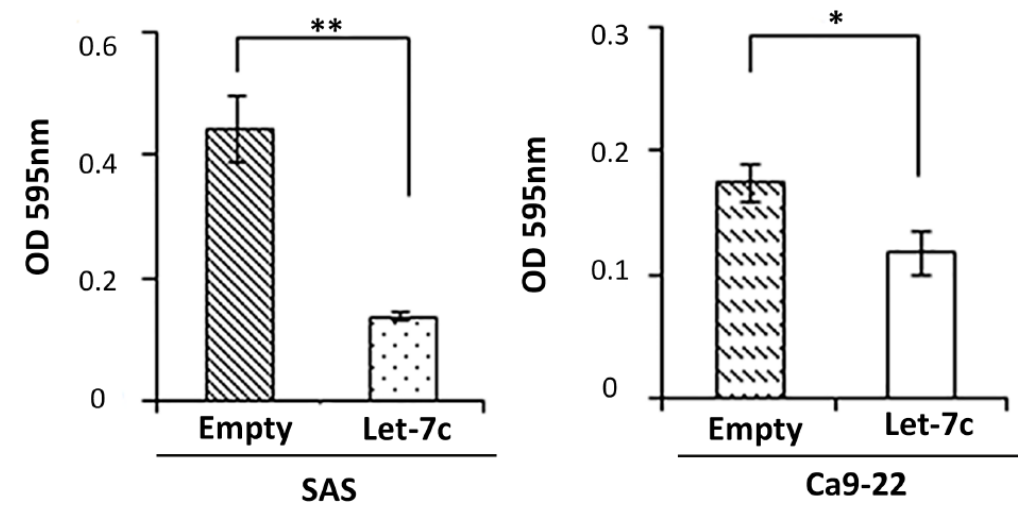

$\mathbf{F}$

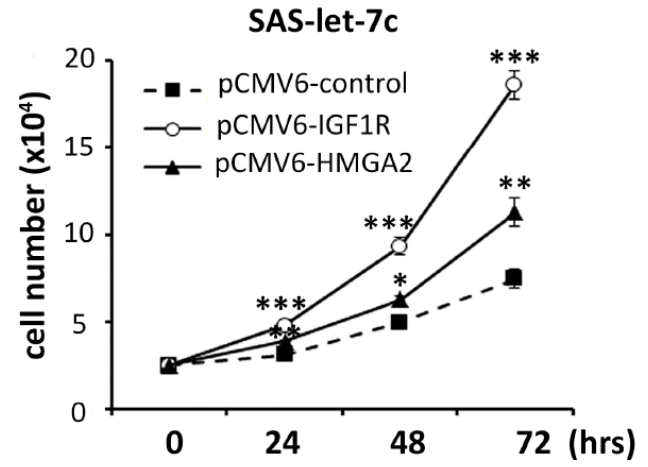

G

SAS-let-7c

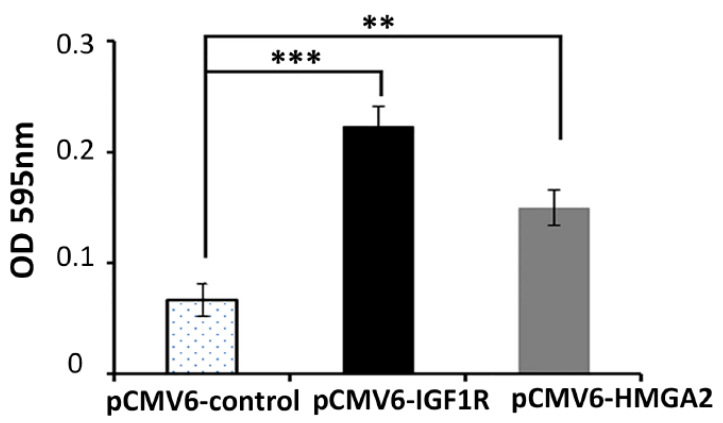

Figure 3: Let-7c inhibits colony formation, proliferation, and migration in HNSCC cell lines. HNSCC cell lines SAS and Ca9-22 were transfected with either pCMV-MIR vector or pCMV-MIR-let-7e vector. Cells were subjected to assays of (A, B) colony formation, (C, D) proliferation, and (E) migration to examine growth of in vitro cancer cell cultures. $P$-values were calculated using the Student's $t$-test. Following re-expression of IGFIR or HMGA2 in SAS-let-7c cells using pCMV6-IGF1R or pCMV6-HMGA2, cells were subjected to assays of $(\mathbf{F})$ proliferation and $(\mathbf{G})$ migration. $P$-values of $\mathrm{F}$ and $\mathrm{G}$ were derived from two-way ANOVA and one-way ANOVA followed by Bonferroni correction, respectively. ${ }^{*} P<0.05 ;{ }^{* *} P<0.01 ;{ }^{* * *} P<0.001$. 


\section{Silencing of IGF1R and HMGA2 potentially contributes to suppression of colony formation, cell proliferation, migration, and EMT in HNSCC cells}

We confirmed that mRNA and protein levels of IGF1R and HMGA2 were significantly down-regulated in SAS cells after transfection with the corresponding siRNAs (Supplementary Figure 4). We examined cell colony formation in siRNA-treated SAS cells. The number of colonies was remarkably smaller in both types of siRNA-transfected cells than in control siRNAtransfected cells (Figure 6A). In the proliferation assay, both types of siRNA-transfected cells grew significantly more slowly than control siRNA-transfected cells (Figure 6B). Migratory cells were observed less frequently in $I G F 1 R$ and HMGA2 siRNA-transfected cells than control siRNA-transfected cells (Figure 6C). These results suggest that reduction of $I G F 1 R$ and HMGA2 contributes to suppression of colony formation, cell proliferation, and migration in HNSCC cells.

To investigate the mechanism underlying cell migration, we evaluated the EMT process using $I G F 1 R$ and $H M G A 2$ siRNA-transfected cells. E-cadherin protein levels were significantly up-regulated in both types of siRNA-transfected SAS cells compared to the control.

A

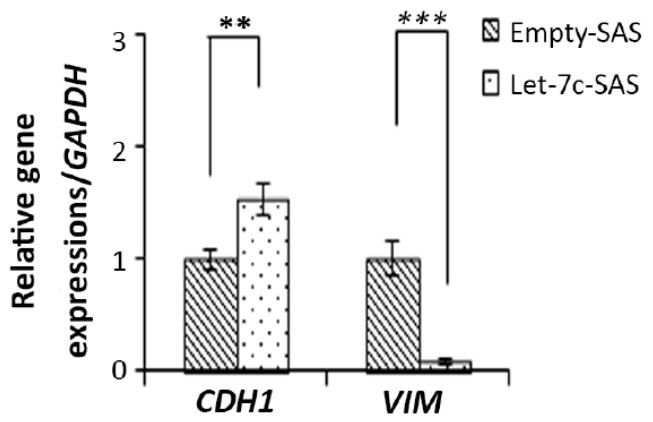

C

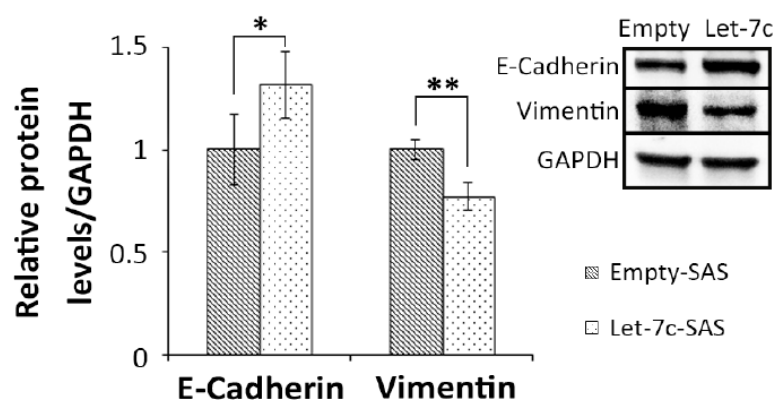

In contrast, vimentin protein levels were down-regulated (Figure 6D, 6E). Taken together, these findings indicate that reduction of IGFIR and HMGA2 inhibits cell migration by inducing the mesenchymal to epithelial transition process.

\section{DISCUSSION}

Aberrant expression of miRNAs has been found in various malignant tumors. Tumor growth and metastasis are critical for tumor progression, and miRNAs are closely involved in this process through their actions on target genes. Many researchers have reported that let- $7 \mathrm{c}$ acts as a tumor suppressor and is down-regulated during tumorigenesis of various types of cancers, including lung, colorectal and prostate cancers [23-26]. In our previous study, we found that let-7c was significantly downregulated in HNSCC tumor tissues compared to adjacent non-tumor tissues and contributes to tumor progression [10], although HNSCCs include various tumors originating from oral cavity, hypopharynx, oropharynx, nasopharynx and larynx with difference in epidemiology, etiology and therapeutic approach. We used TargetScan Human, an online database for prediction of miRNA targets, to show that $I G F 1 R$ and $H M G A 2$ were the target genes of let-7c. Western blot analysis revealed upregulation of $I G F 1 R$

B

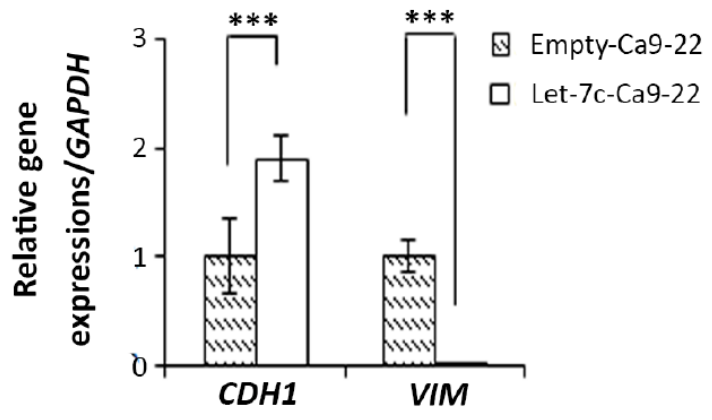

D

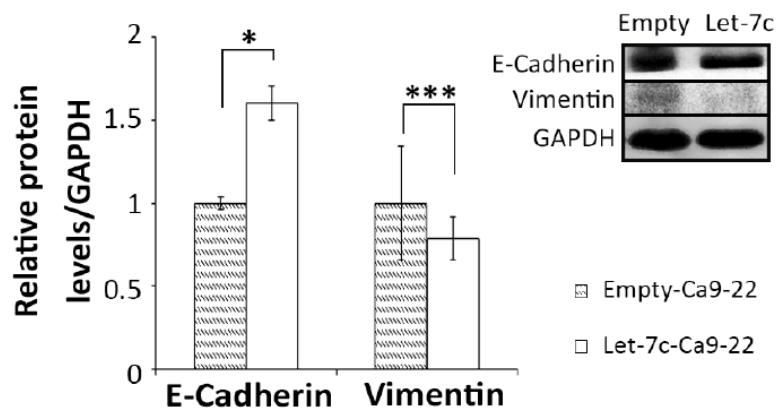

Figure 4: Let-7c inhibits EMT in HNSCC cell lines. (A, B) CDH1 and VIM mRNA levels in let-7c-expressing cell lines were determined by RT-qPCR, and (C, D) E-cadherin and vimentin protein levels were examined by western blot analysis in SAS and Ca922, respectively, two HNSCC cell lines stably expressing let-7c. GAPDH served as loading control. $P$-values were calculated using the Student's $t$-test. ${ }^{*} P<0.05 ;{ }^{* *} P<0.01 ;{ }^{* * *} P<0.001$. 
A

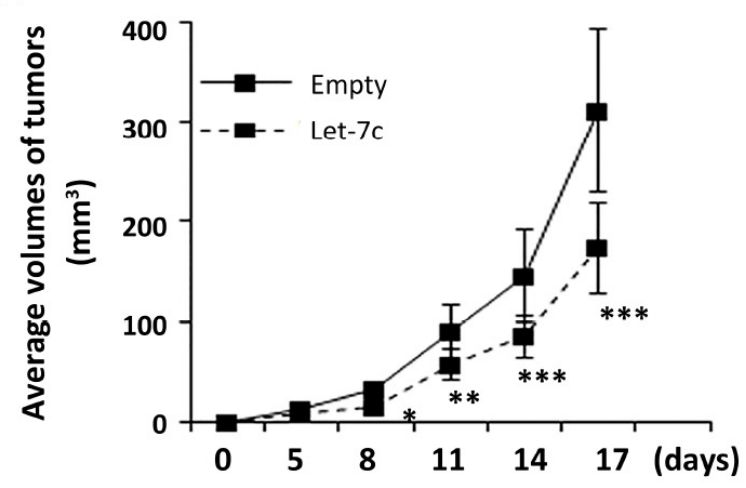

C

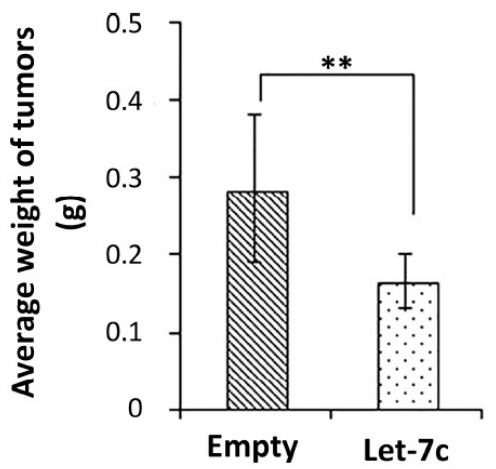

B
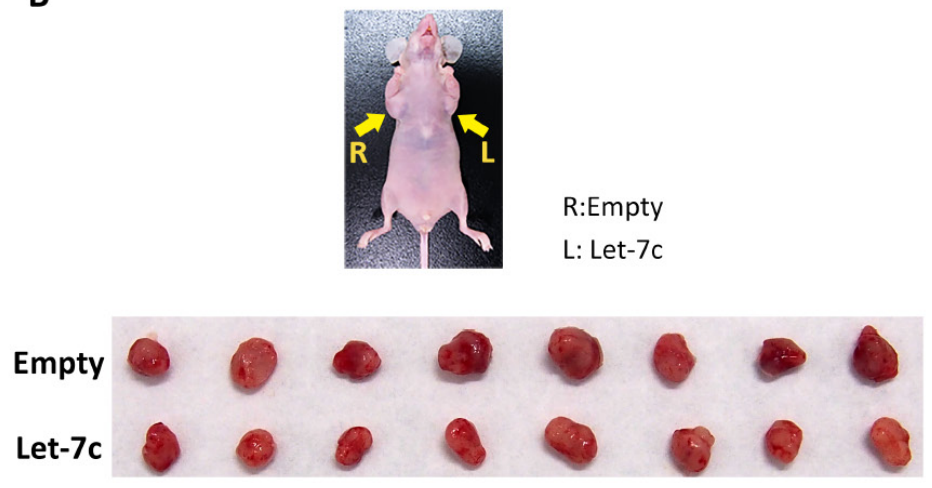

D
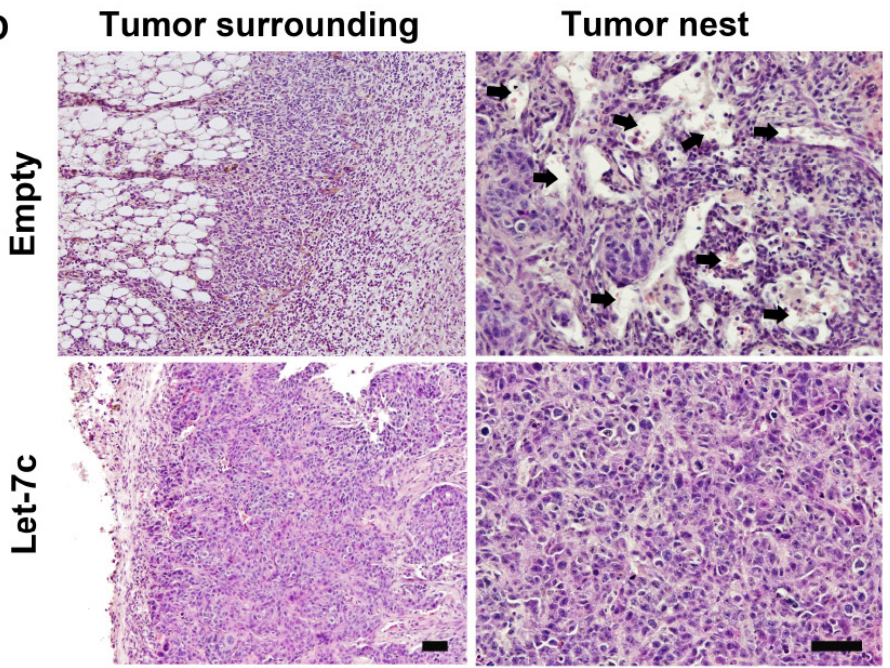

Tumor nest

vimentin

$\mathbf{E}$

IGF1R

HMGA2
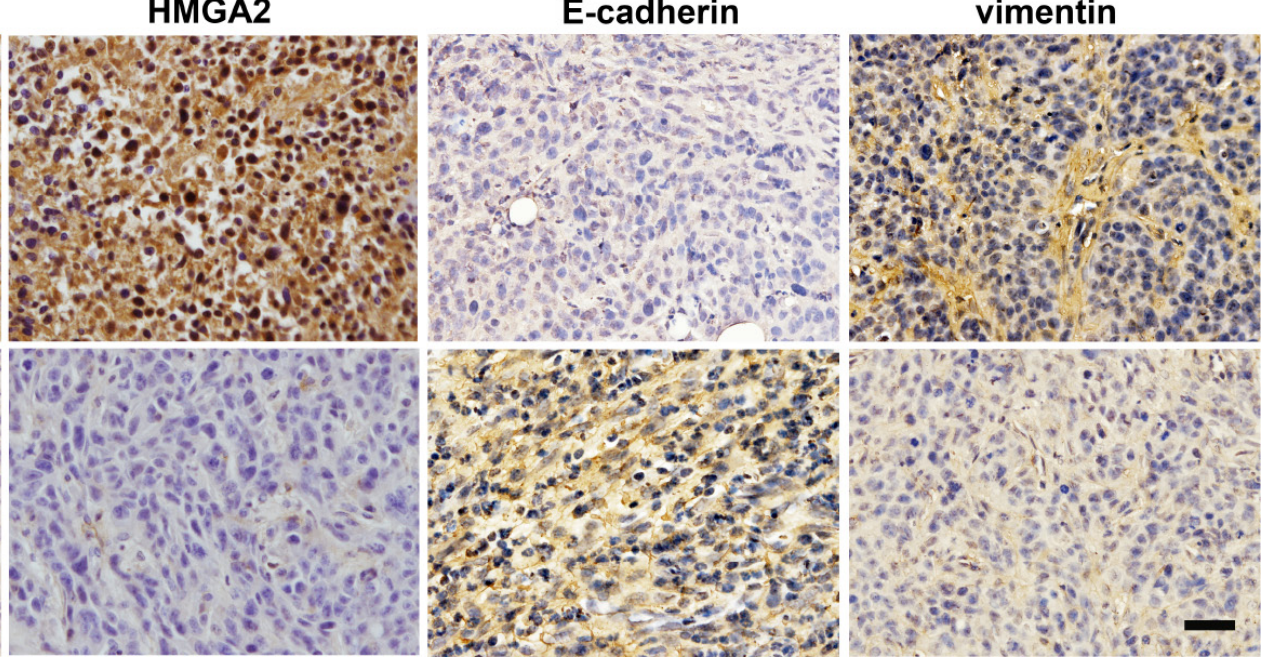

Figure 5: Let-7c inhibits HNSCC tumor growth and infiltration. (A) Growth curves were drawn by measuring tumor volumes at the indicated times. (B) Image of subcutaneous xenografts in the mouse flanks (the arrows indicate tumor locations in a mouse injected with (L) SAS cells stably expressing let-7c or (R) control SAS cells) and excised tumors. (C) Weight of xenograft tumors. (D) H\&E staining demonstrating growth properties. Arrows point to blood vessels in the cancer nests. (E) Representative IHC staining of IGF1R, HMGA2, E-cadherin, and vimentin in the xenograft tumors. Nuclei were counterstained with hematoxylin. Original magnification $\times 100$ and $\times 200$; bars represent $50 \mu \mathrm{m} . P$-values of differences between let- $7 \mathrm{c}$ and control tumors were calculated using the Student's paired $t$-test. ${ }^{*} P<0.05$, ${ }^{* *} P<0.01,{ }^{* * *} P<0.001$. 
and $H M G A 2$ corresponding to the downregulation of let7c in HNSCC tissues. High-risk human papillomaviruses (HPVs) have been implicated in the pathogenesis of a subset of HNSCCs, mainly arising from the oropharynx $[27,28]$. To date, mounting evidence indicates that HPVs may regulate cellular miRNA expression through their

A

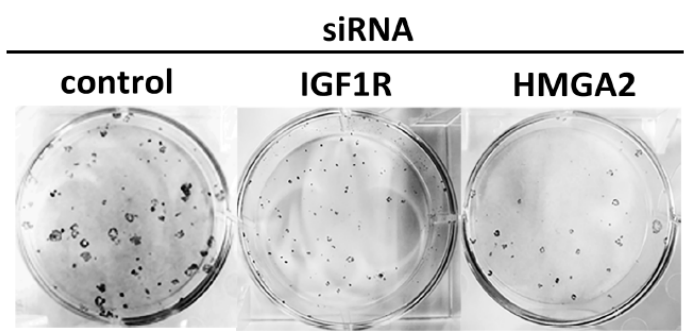

B

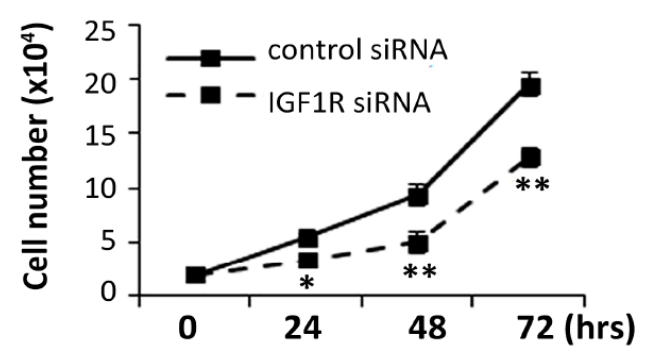

C

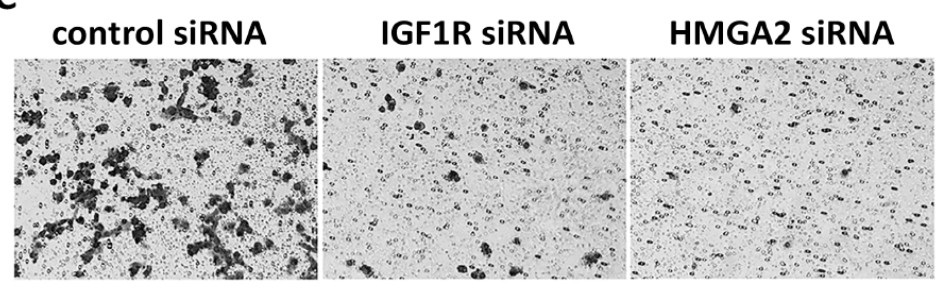

E6 and E7 oncoproteins [29]. Recent studies showed that HNSCCs with IGF1R or HMGA2 expression are associated with HPV-negative status [30-32]. We checked HPV status in HNSCC patients by staining the cyclindependent kinase inhibitor p16, which is considered to be a biomarker for HPV-related diseases [33] (Supplementary
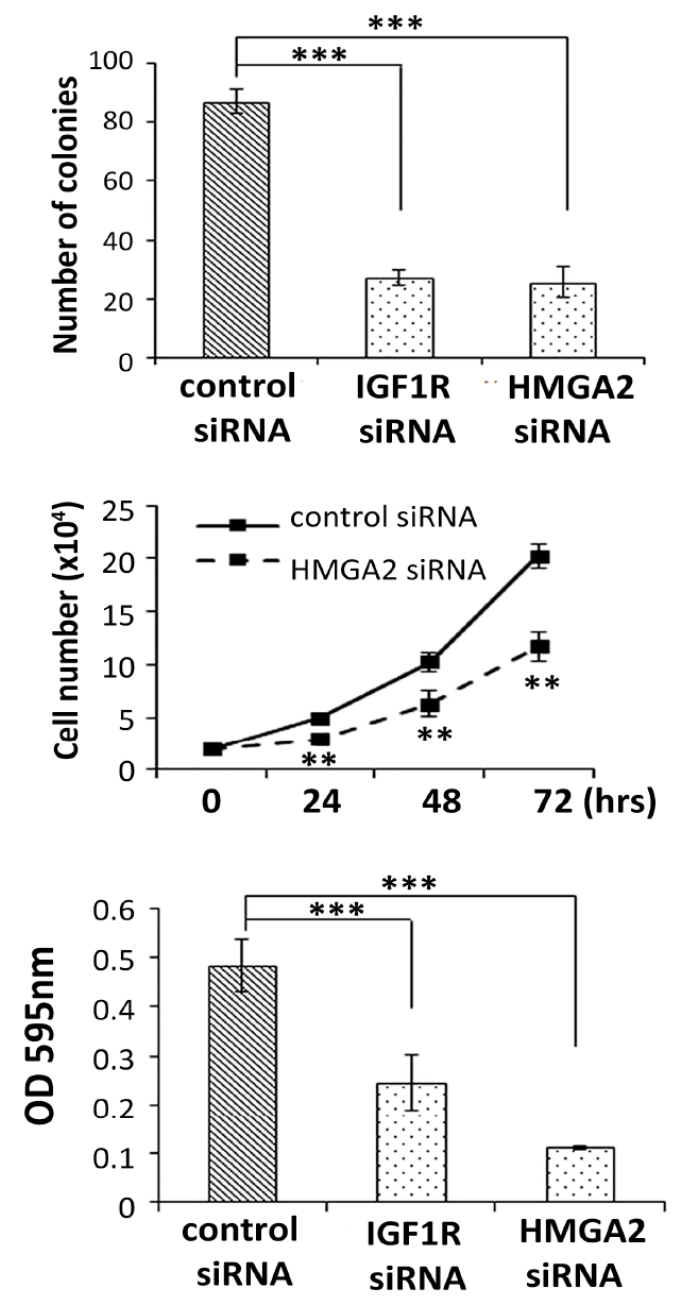

D

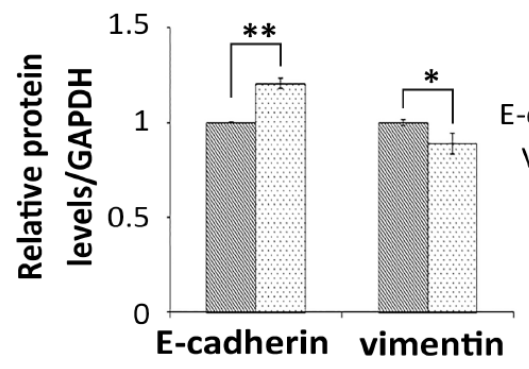

E

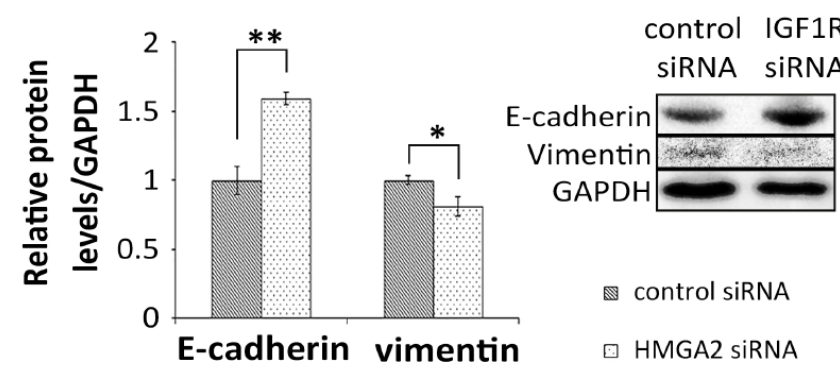

Figure 6: Reduction of IGF1R and $H M G A 2$ inhibits colony formation, cell proliferation, migration, and EMT in HNSCC cells. IGFIR and HMGA2 were knocked down using siRNAs in the HNSCC cell line SAS. Cells were subjected to assays of (A) colony formation, (B) proliferation, and (C) migration to examine growth of in vitro cancer cell cultures. (D, E) Levels of EMT-related proteins E-cadherin and vimentin were determined by western blot in SAS cells transfected with (D) IGF1R siRNA or (E) HMGA2. $P$-values of A and $\mathrm{C}$ were achieved using one-way ANOVA, followed by Bonferroni correction. (B, D, E) $P$-values were calculated using the Student's $t$-test. ${ }^{*} P<0.05 ;{ }^{* *} P<0.01 ;{ }^{* * *} P<0.001$. 
Table 1). However, no significant differences in IGF1R and HMGA2 expression levels were observed between HPV-positive and -negative groups, with the limitation probably due to small sample size. MiRNAs can reduce gene expression by binding to the 3 '-UTR of the target gene, causing mRNA degradation or suppression of translation. We demonstrated the potential binding of let-7c to the 3'-UTRs of IGFIR and HMGA2 mRNAs using luciferase reporter assays. Furthermore, exogenous expression of let-7c in HNSCC cells down-regulated $I G F 1 R$ and HMGA2 levels both in vitro and in vivo. These results indicate that let-7c negatively regulates $I G F 1 R$ and $H M G A 2$ expression by binding to the $3^{\prime}$-UTRs of these genes in HNSCC.

The present study demonstrated that overexpression of let-7c resulted in suppression of cell proliferation, migration, and EMT in HNSCC cells in vitro. EMT is critical for tumor metastasis, and high levels of let-7c have been reported to control EMT in various tumor cells $[22,34]$, although there are no reports specific to HNSCC. For the first time, we confirmed that overexpression of let-7c increased E-cadherin and decreased vimentin in a nude mouse xenograft model. Moreover, let-7c suppressed tumor growth and infiltration at the invasive front in vivo. Thus, these results indicated that let-7c plays a role in suppression of HNSCC development. miRNAtargeting therapies have been an area of intense interest to pharmaceutical companies, and let-7 is currently being developed as a potential miRNA replacement treatment for cancer. Although details of which cancer types are being investigated have not been disclosed, it will be interesting to see whether the delivery of miRNA mimetics can indeed have a therapeutic impact [35].

To clarify the mechanism of action of let-7c, we tried to elucidate the relation between let-7c and its targets: $I G F 1 R$ and $H M G A 2$. We demonstrated that the expression levels of $I G F 1 R$ and $H M G A 2$ were significantly higher in HNSCC tumor tissues compared to non-tumor tissues, corresponding to downregulation of let-7c. Elevated expression of let-7c in HNSCC cells can downregulate $I G F 1 R$ and $H M G A 2$ levels. Silencing of IGF1R and $H M G A 2$ inhibited cell growth, migration, and EMT, which indicates the oncogenic roles of these genes in HNSCC progression. The IGF signaling system has been implicated in the pathogenesis of various human cancers, including HNSCC [36]. The IGF1 receptor has emerged as a potential target molecule for cancer treatment $[13,37,38]$. Moreover, $I G F 1 R$ has been reported to be essential for sustaining mesenchymal morphologies and plays an important role in regulating EMT in breast cancer [17]. HMGA2 is abundant during embryogenesis and tumorigenesis, but is rarely present in normal adult tissues [39]. In addition, $H M G A 2$ expression can be detected in various cancers and is correlated with malignant degree and metastatic potential $[16,40,41]$. The oncogenic properties of $H M G A 2$ have been shown to influence a variety of biological processes, including tumor growth [42], DNA damage response [43], and EMT [44-46]. HMGA2 has been associated with an aggressive cancer phenotype and induction of EMT by suppressing E-cadherin transcription in tongue cancer [18]. A recent report showed that cell proliferation was regulated by the $H M G A 2-I G F 2 B P 2$ axis, which includes $I G F 1 R$, suggesting the presence of interactions between $H M G A 2$ and $I G F 1 R$ [47]. Our findings and the literature demonstrate that let-7c--mediated regulation of IGF1R and HMGA2 may affect the aggressiveness of HNSCC through EMT. Recent studies [48, 49] indicated the possibility that miRNA-based cancer therapy is to achieve specific, effective, and safe delivery of therapeutic miRNAs into cancer cells. Therefore, the results from this study offer a new therapeutic strategy for HNSCC treatment that warrants further investigation in future clinical studies. In conclusion, our study identifies let-7c as a novel tumor suppressor of HNSCC that inhibits cell proliferation, migration, and EMT through repression of $I G F 1 R$ and $H M G A 2$ expression.

\section{MATERIALS AND METHODS}

\section{Patient recruitment and sample collection}

Paired tissue samples were collected from 15 patients with HNSCC who underwent surgery at the Department of Otorhinolaryngology-Head and Neck Surgery, Mie University Hospital, between 2012 and 2013. Clinical characteristics, including patient age, sex, TNM staging, and the status of HPV infection determined by p16 IHC staining are listed in Supplementary Table 1. Tissue specimens were immediately steeped in RNAlater (Ambion, Carlsbad, CA, USA) at $4^{\circ} \mathrm{C}$ for $24 \mathrm{~h}$ and subsequently stored at $-80^{\circ} \mathrm{C}$ until analysis. This study was approved by the Mie University Graduate School of Medicine Ethical Committee (No. 2445). Written informed consent was obtained from each patient before the study.

\section{Cell culture}

Non-malignant nasopharyngeal epithelial cell line NP69 was cultivated in keratinocyte serum-free medium (Gibco, Carlsbad, CA, USA). The HNSCC cell lines SAS, Ca9-22, and H0-1-u-1 (derived from tongue, gingiva, and mouth floor, respectively) were obtained from RIKEN BRC Cell Bank (Tsukuba, Japan). All these HNSCC cell lines were maintained in RPMI-1640 medium with $10 \%$ fetal bovine serum.

\section{miRNA plasmid transfection}

The let-7c expression vector pCMV-MIR-let-7c and the pCMV-MIR vector were obtained from Origene (Rockville, MD, USA). Both vectors were monitored using green fluorescent protein. The let-7c expression vector and empty vector were transfected into SAS cells 
and Ca9-22 cells using FuGENE HD Transfection Reagent (Promega, Madison, WI, USA). Stable clones expressing let-7c (SAS-let-7c and Ca9-22-let-7c) or empty vector (SAS-empty and Ca9-22-empty) were obtained by G418 (Calbiochem, La Jolla, CA, USA; $600 \mu \mathrm{g} / \mathrm{ml}$ and $200 \mu \mathrm{g} /$ $\mathrm{ml}$, respectively) selection for 2 weeks. Three vectors (Origene), namely, pCMV6-control, pCMV6-IGF1R, and pCMV6-HMGA2, were used for the rescue study.

\section{Reverse transcription and RT-qPCR}

Total RNA from cell lines was extracted using TRIzol reagent (Ambion). The integrity and quantity of total RNA were confirmed by gel electrophoresis and a NanoDrop 2000 spectrophotometer (NanoDrop, Wilmington, DE, USA). cDNA was synthesized from $500 \mathrm{ng}$ RNA using a miScript Reverse Transcription Kit (Qiagen, Hilden, Germany). RT-qPCR was performed in duplicate using a miScript SYBR Green PCR kit (Qiagen) for samples with the miScript Universal Primer and the miRNA-specific forward primers. Expression levels of mRNA and miRNA were normalized by GAPDH and small nuclear RNA RNU6B, respectively. All amplifications were carried out in an ABI Step One Plus Real-time PCR System (Applied Biosystems, Singapore, Singapore).

\section{Western blotting}

HNSCC tissues and cell lines were lysed for 10 min in ice-cold RIPA buffer (Cell Signaling Technology, Beverly, MA, USA) containing protease inhibitor cocktail tablets (Sigma-Aldrich, St. Louis, MO, USA) and then centrifuged at $14,000 \mathrm{~g}$ for $20 \mathrm{~min}$ at $4{ }^{\circ} \mathrm{C}$. Supernatants were collected and stored at $-80^{\circ} \mathrm{C}$. Protein concentrations were determined using a BCA (bicinchoninic acid) assay kit (Pierce, Tewksbury, MA, USA). SDS-treated proteins were separated on SuperSepAce 5-20\% polyacrylamide gels (Wako Pure Chemical Industries, Osaka, Japan), and transferred to PVDF membranes. The PVDF membranes were then cut according to the molecular weight markers and membranes were stained using different antibodies. Primary antibodies against IGF1R- $\beta$ (1:1000, \#9750), HMGA2 (1:1000, \#8179), E-cadherin (1:1000, \#3195), and vimentin $(1: 1000, \# 5741)$ were obtained from Cell Signaling Technology. Immunoreactive bands were detected with a chemiluminescence reagent kit (ECL Prime; Amersham Bioscience, Arlington Heights, IL, USA) and quantified by densitometry with Image $\mathrm{J}$ software (NIH, Bethesda, MD, USA). GAPDH (1:2500; ab9485; Abcam, Cambridge, UK) was blotted on the same membrane as a loading control.

\section{Dual-luciferase reporter assay}

A pmirGLO Dual-Luciferase miRNA Target Expression Vector was used for 3'-UTR luciferase assays (Promega). The putative target oncogenes of tumor suppressor let-7c were selected based on the TargetScan Human online database (Release 7.0: August 2015, http://www.targetscan.org/). There are three and seven predicted binding sites of let-7 $\mathrm{c}$ in the $3^{\prime}$-UTRs of $I G F 1 R$ and $H M G A 2$, respectively. Predictions are ranked by their probability of conserved targeting $\left(\mathrm{P}_{\mathrm{CT}}\right)$ (Supplementary Table 2). To design the oligonucleotide sequences of $I G F 1 R$ and HMGA2, we chose the binding sites of let$7 \mathrm{c}$ that achieved the highest $\mathrm{P}_{\mathrm{CT}}$ scores. Oligonucleotide sequences of $I G F I R$ and $H M G A 2$ containing the putative binding sites of let-7c were designed as shown in Supplementary Table 3. The double-stranded annealing products were inserted downstream of the firefly luciferase reporter in the pmirGLO dual-luciferase miRNA target expression vector. SAS cells were plated in 96-well plates for $24 \mathrm{~h}$, then co-transfected with $50 \mathrm{ng}$ of PCMV-MIR control vector or PCMV-MIR-let-7c vector and $100 \mathrm{ng}$ dual-luciferase vector containing either wildtype or mutant $3^{\prime}$-UTR. At $24 \mathrm{~h}$ after transfection, the luciferase activity was measured with the Dual-luciferase Reporter Assay System (Promega).

\section{Colony formation and cell proliferation assay}

Cell lines stably transfected with let-7c or empty vector (SAS-let-7c, Ca9-22-let-7c; SAS-empty, Ca9-22empty) were seeded for colony formation in 6-well plates at 500 cells per well. After 9 days, colonies were scored using a microscope by adding Giemsa (Merck, Darmstadt, Germany). Colonies were counted only if the diameter of a single colony was larger than $75 \mu \mathrm{m}$ in diameter. Each assay was performed in triplicate on two independent occasions. For cell proliferation assays, growth curves of cell lines stably transfected with let-7c or empty vector (SAS-let-7c, Ca9-22-let-7c; SAS-empty, Ca9-22-empty) were monitored by cell counting. Transfected cells were seeded at a density of $5 \times 10^{4}$ cells $/ \mathrm{mL}$ per well in 6-well plates. The cells were counted using the TC 20 Automated Cell Counter (Bio-Rad, Hercules, CA, USA).

\section{Migration assay}

Cell migration assays were performed using the CytoSelect Cell Migration Assay Kit $(8-\mu \mathrm{m}$ pore membrane filter; Colorimetric Format; Cell BioLabs, San Diego, CA, USA). To study the role of let- $7 \mathrm{c}$ in tumor biology, cells were suspended in serum-free medium $\left(0.15 \times 10^{6}\right.$ transfected cells/well $)$ and placed in the upper chamber of the migration plate, and medium containing $10 \%$ FBS was placed in the lower chamber. After incubation for $24 \mathrm{~h}$ and removal of non-migratory cells, cells that migrated through the filter were stained. Each filter with migratory cells was extracted, and relative migration level was quantified by measuring absorption at $595 \mathrm{~nm}$ using a microplate reader (Model 680, Bio-Rad). 


\section{IHC and ICC study}

For IHC analysis, standard immunoperoxidase methods were used to examine the distribution of IGF1R and HMGA2 in HNSCC tissues and adjacent non-tumor tissues. After deparaffinization and rehydration, antigen was retrieved in $5 \%$ urea buffer by microwave heating for $5 \mathrm{~min}$, and then inctubated in $1 \% \mathrm{H}_{2} \mathrm{O}_{2}$ for $30 \mathrm{~min}$ to block endogenous peroxidase activity. Sections of $6-\mu \mathrm{m}$ thickness were incubated overnight at room temperature with the following antibodies: rabbit monoclonal IGF1R- $\beta$ (1:200) and rabbit monoclonal anti-HMGA2 (1:100). Nuclei were counterstained with hematoxylin, with the exception of HMGA2 since its immunostaining is located in nuclei. For ICC analysis, cells stably transfected with let-7c were fixed with $4 \%(\mathrm{v} / \mathrm{v})$ formaldehyde in phosphate buffered saline (PBS) for $10 \mathrm{~min}$ at room temperature and washed three times with PBS. The cells were treated with $1 \%(\mathrm{v} / \mathrm{v})$ Triton X-100 for $20 \mathrm{~min}$, then incubated with $5 \%(\mathrm{w} / \mathrm{v})$ skim milk for $60 \mathrm{~min}$ at room temperature. Immunofluorescence was performed by overnight incubation at room temperature with rabbit monoclonal IGF1R- $\beta$ (1:1600), rabbit monoclonal antiHMGA2 (1:400), rabbit monoclonal E-cadherin (1:200), and vimentin (1:100), all obtained from Cell Signaling Technology. The cells were then incubated with fluorescent secondary antibodies (Alexa Fluor 594-labeled goat antirabbit IgG, 1:400 each, Molecular Probes) for $2 \mathrm{~h}$. Nuclei were stained with DAPI (SouthernBiotech, Birmingham, AL, USA) and the stained cells were examined under a fluorescence microscope (BX53; Olympus, Tokyo, Japan). The number of positively staining cells was analyzed using ImageJ software (ver. 1.48).

\section{Nude mice xenograft model and hematoxylin \& eosin staining}

Four-week-old male BALB/c athymic nu/nu mice (Japan SLC, Hamamatsu, Japan, weight range 16-19 g) were used in these experiments and maintained at the Institute of Laboratory Animals at Mie University. All animal experiments were performed according to the Mie University guidelines for laboratory animals (approval No. 26-19). A total of 8 animals were housed in ventilated cages under a $12 \mathrm{~h}$ dark/light cycle at constant humidity and temperature. Animals were permitted free access to sterile water and standard laboratory chow. Subcutaneous xenografts were established by inoculating $2 \times 10^{6}$ let- $7 \mathrm{c}$ stably transfected SAS cells into the left flank, or an equal number of empty vector-transfected cells into the right flank. The tumor volume was measured with a caliper (model 530-312; range 0-150 mm; Mitutoyo, Kawasaki, Japan) and calculated using the following formula: tumor volume $\left(\mathrm{mm}^{3}\right)=$ length $\times$ width $^{2} / 2$, where length and width were the longer and shorter dimensions of the tumor, respectively. Seventeen days after the implantation, the mice were sacrificed and the tumors were removed and weighed. Tumors were fixed in $4 \%$ formaldehyde. Primary antibodies against IGF1R- $\beta$ (1:200), HMGA2 (1:100), E-cadherin (1:100), and vimentin (1:100) were used for IHC analysis.

\section{Abbrevations}

HNSCC: Head and neck squamous cell carcinoma; $I G F 1 R$ : insulin-like growth factor 1 receptor; $H M G A 2$ : high mobility group AT-hook 2; EMT: epithelialmesenchymal transition; 3'-UTR: 3'-untranslated region; HPV: human papilloma virus.

\section{Author contributions}

B.H., K.T. and M.M. conceived and designed the study. B.H. acquired and analyzed the data. K.M. and N.M. gave assistance on luciferase assay and IHC study. H.I. and S.N assisted HNSCC sample collections. B.H. wrote the manuscript. H.I., K.M., Y.H., S.O., N.M., K.T. and M.M. revised the manuscript, and all authors read and approved of the final manuscript.

\section{ACKNOWLEDGMENTS AND FUNDING}

This work was supported in part by JSPS KAKENHI Grant Numbers JP23659327, JP25293149, and JP16H05255 (MM). We also thank the Merk Serono Company (KT).

\section{CONFLICTS OF INTEREST}

The authors declare no conflict of interest.

\section{REFERENCES}

1. Ferlay J, Soerjomataram I, Ervik M, Dikshit R, Eser S, Mathers C, Rebelo M, Parkin D, Forman D, Bray F. GLOBOCAN 2012 v1. 0, Cancer Incidence and Mortality Worldwide: IARC CancerBase No. 11. 2013. Lyon, France: International Agency for Research on Cancer; 2014.

2. Sanderson RJ, Ironside JA. Squamous cell carcinomas of the head and neck. BMJ. 2002; 325:822-827.

3. Jemal A, Bray F, Center MM, Ferlay J, Ward E, Forman D. Global cancer statistics. CA Cancer J Clin. 2011; 61:69-90.

4. Cho JK, Hyun SH, Choi JY, Choi N, Kim MJ, Lee SH, Baek KH, Jeong HS. Prognostic significance of clinical and 18 F-FDG PET/CT parameters for post-distant metastasis survival in head and neck squamous cell carcinoma patients. J Surg Oncol. 2016; 114:888-894.

5. Iorio MV, Croce CM. MicroRNA dysregulation in cancer: diagnostics, monitoring and therapeutics. A comprehensive review. EMBO Mol Med. 2012; 4:143-159. 
6. Baek D, Villen J, Shin C, Camargo FD, Gygi SP, Bartel DP. The impact of microRNAs on protein output. Nature. 2008; 455:64-71.

7. Lewis BP, Burge CB, Bartel DP. Conserved seed pairing, often flanked by adenosines, indicates that thousands of human genes are microRNA targets. Cell. 2005; 120:15-20.

8. Esquela-Kerscher A, Slack FJ. Oncomirs - microRNAs with a role in cancer. Nat Rev Cancer. 2006; 6:259-269.

9. Li JH, Liu S, Zhou H, Qu LH, Yang JH. starBase v2.0: decoding miRNA-ceRNA, miRNA-ncRNA and proteinRNA interaction networks from large-scale CLIP-Seq data. Nucleic Acids Res. 2014; 42:D92-97.

10. Hou B, Ishinaga H, Midorikawa K, Shah SA, Nakamura S, Hiraku Y, Oikawa S, Murata M, Takeuchi K. Circulating microRNAs as novel prognosis biomarkers for head and neck squamous cell carcinoma. Cancer Biol Ther. 2015; 16:1042-1046.

11. Deng WY, Li N, Wan XB, Luo SX, Zhang YW. Phosphorylated insulin-like growth factor-1 receptor expression predicts poor prognosis of Chinese patients with gastric cancer. Med Oncol. 2014; 31:141.

12. Wu JJ, Zhang SZ, Shan JL, Hu ZJ, Liu XY, Chen LR, Ren XC, Yao LF, Sheng HQ, Li L, Ann D, Yen Y, Wang J, et al. Elevated HMGA2 expression is associated with cancer aggressiveness and predicts poor outcome in breast cancer. Cancer Lett. 2016; 376:284-292.

13. Li R, Pourpak A, Morris SW. Inhibition of the insulinlike growth factor-1 receptor (IGF1R) tyrosine kinase as a novel cancer therapy approach. J Med Chem. 2009; 52:4981-5004.

14. Malek A, Bakhidze E, Noske A, Sers C, Aigner A, Schafer $\mathrm{R}$, Tchernitsa O. HMGA2 gene is a promising target for ovarian cancer silencing therapy. Int J Cancer. 2008; 123:348-356

15. Heidegger I, Kern J, Ofer P, Klocker H, Massoner P. Oncogenic functions of IGF1R and INSR in prostate cancer include enhanced tumor growth, cell migration and angiogenesis. Oncotarget. 2014; 5:2723-2735. https://doi. org/10.18632/oncotarget.1884.

16. Wang X, Liu X, Li AY, Chen L, Lai L, Lin HH, Hu S, Yao L, Peng J, Loera S, Xue L, Zhou B, Zhou L, et al. Overexpression of HMGA2 promotes metastasis and impacts survival of colorectal cance rs. Clin Cancer Res. $2011 ; 17: 2570-80$.

17. Taliaferro-Smith L, Oberlick E, Liu T, McGlothen T, Alcaide T, Tobin R, Donnelly S, Commander R, Kline E, Nagaraju GP, Havel L, Marcus A, Nahta R, et al. FAK activation is required for IGF1R-mediated regulation of EMT, migration, and invasion in mesenchymal triple negative breast cancer cells. Oncotarget. 2015; 6:4757-72. https:// doi.org/10.18632/oncotarget.3023.

18. Zhao XP, Zhang H, Jiao JY, Tang DX, Wu YL, Pan CB. Overexpression of HMGA2 promotes tongue cancer metastasis through EMT pathway. J Transl Med. 2016; $14: 26$.

19. Mountzios G, Kostopoulos I, Kotoula V, Sfakianaki I, Fountzilas E, Markou K, Karasmanis I, Leva S, Angouridakis N, Vlachtsis K, Nikolaou A, Konstantinidis I, Fountzilas G. Insulin-like growth factor 1 receptor (IGF1R) expression and survival in operable squamous-cell laryngeal cancer. PLoS One. 2013; 8:e54048.

20. Hugo H, Ackland ML, Blick T, Lawrence MG, Clements JA, Williams ED, Thompson EW. Epithelial-mesenchymal and mesenchymal - Epithelial transitions in carcinoma progression. J Cell Physiol. 2007; 213:374-383.

21. Sugimoto $H$, Ito $M$, Hatano $M$, Kondo $S$, Suzuki $S$, Yoshizaki T. Roles of epithelial-mesenchymal transition in squamous cell carcinoma of the temporal bone. Otol Neurotol. 2011; 32:483-487.

22. Ahmad A, Maitah MY, Ginnebaugh KR, Li Y, Bao B, Gadgeel SM, Sarkar FH. Inhibition of Hedgehog signaling sensitizes NSCLC cells to standard therapies through modulation of EMT-regulating miRNAs. J Hematol Oncol. $2013 ; 6: 77$

23. Zhao B, Han H, Chen J, Zhang Z, Li S, Fang F, Zheng Q, Ma Y, Zhang J, Wu N, Yang Y. MicroRNA let-7c inhibits migration and invasion of human non-small cell lung cancer by targeting ITGB3 and MAP4K3. Cancer Lett. 2014; $342: 43-51$

24. Han HB, Gu J, Zuo HJ, Chen ZG, Zhao W, Li M, Ji DB, Lu YY, Zhang ZQ. Let-7c functions as a metastasis suppressor by targeting MMP11 and PBX3 in colorectal cancer. J Pathol. 2012; 226:544-555.

25. Nadiminty N, Tummala R, Lou W, Zhu Y, Zhang J, Chen X, eVere White RW, Kung HJ, Evans CP, Gao AC. MicroRNA let-7c suppresses androgen receptor expression and activity via regulation of Myc expression in prostate cancer cells. J Biol Chem. 2012; 287:1527-37.

26. Nadiminty N, Tummala R, Lou W, Zhu Y, Shi XB, Zou JX, Chen H, Zhang J, Chen X, Luo J, deVere White RW, Kung HJ, Evans CP, et al. MicroRNA let-7c is downregulated in prostate cancer and suppresses prostate cancer growth. PLoS One. 2012; 7 :e32832.

27. Rampias T, Sasaki C, Weinberger P, Psyrri A. E6 and e7 gene silencing and transformed phenotype of human papillomavirus 16-positive oropharyngeal cancer cells. J Natl Cancer Inst. 2009; 101:412-423.

28. Economopoulou P, Perisanidis C, Giotakis EI, Psyrri A. The emerging role of immunotherapy in head and neck squamous cell carcinoma (HNSCC): anti-tumor immunity and clinical applications. Ann Transl Med. 2016; 4:173.

29. Zheng ZM, Wang X. Regulation of cellular miRNA expression by human papillomaviruses. Biochim Biophys Acta. 2011; 1809:668-677.

30. Dale OT, Aleksic T, Shah KA, Han C, Mehanna H, Rapozo DC, Sheard JD, Goodyear P, Upile NS, Robinson M, Jones TM, Winter S, Macaulay VM. IGF-1R expression is 
associated with HPV-negative status and adverse survival in head and neck squamous cell cancer. Carcinogenesis. 2015; 36:648-655.

31. Gunther K, Foraita R, Friemel J, Gunther F, Bullerdiek J, Nimzyk R, Markowski DN, Behrens T, Ahrens W. The Stem Cell Factor HMGA2 Is Expressed in Non-HPV-Associated Head and Neck Squamous Cell Carcinoma and Predicts Patient Survival of Distinct Subsites. Cancer Epidemiol Biomarkers Prev. 2017; 26:197-205.

32. Matsumoto F, Fujimaki M, Ohba S, Kojima M, Yokoyama J, Ikeda K. Relationship between insulin-like growth factor-1 receptor and human papillomavirus in patients with oropharyngeal cancer. Head Neck. 2015; 37:977-81.

33. Hiraku Y, Tabata T, Ma N, Murata M, Ding X, Kawanishi S. Nitrative and oxidative DNA damage in cervical intraepithelial neoplasia associated with human papilloma virus infection. Cancer Sci. 2007; 98:964-972.

34. Zhang J, Ma L. MicroRNA control of epithelialmesenchymal transition and metastasis. Cancer Metastasis Rev. 2012; 31:653-62.

35. Li Z, Rana TM. Therapeutic targeting of microRNAs: current status and future challenges. Nat Rev Drug Discov. 2014; 13:622-638.

36. Maki RG. Small is beautiful: insulin-like growth factors and their role in growth, development, and cancer. J Clin Oncol. 2010; 28:4985-95.

37. Klinakis A, Szabolcs M, Chen G, Xuan S, Hibshoosh H, Efstratiadis A. Igflr as a therapeutic target in a mouse model of basal-like breast cancer. Proc Natl Acad Sci USA. 2009; 106:2359-64.

38. Bitelman C, Sarfstein R, Sarig M, Attias-Geva Z, Fishman A, Werner H, Bruchim I. IGF1R-directed targeted therapy enhances the cytotoxic effect of chemotherapy in endometrial cancer. Cancer Lett. 2013; 335:153-159.

39. Hammond SM, Sharpless NE. HMGA2, microRNAs, and stem cell aging. Cell. 2008; 135:1013-1016.

40. Piscuoglio S, Zlobec I, Pallante P, Sepe R, Esposito F, Zimmermann A, Diamantis I, Terracciano L, Fusco A, Karamitopoulou E. HMGA1 and HMGA2 protein expression correlates with advanced tumour grade and lymph node metastasis in pancreatic adenocarcinoma. Histopathology. 2012; 60:397-404.
41. Chang KP, Lin SJ, Liu SC, Yi JS, Chien KY, Chi LM, Kao HK, Liang Y, Lin YT, Chang YS, Yu JS. Low-molecularmass secretome profiling identifies HMGA2 and MIF as prognostic biomarkers for oral cavity squamous cell carcinoma. Sci Rep. 2015; 5:11689.

42. Wend P, Runke S, Wend K, Anchondo B, Yesayan M, Jardon M, Hardie N, Loddenkemper C, Ulasov I, Lesniak MS, Wolsky R, Bentolila LA, Grant SG, et al. WNT10B/ beta-catenin signalling induces HMGA2 and proliferation in metastatic triple-negative breast cancer. EMBO Mol Med. 2013; 5:264-279.

43. Singh I, Ozturk N, Cordero J, Mehta A, Hasan D, Cosentino C, Sebastian C, Kruger M, Looso M, Carraro G, Bellusci $\mathrm{S}$, Seeger W, Braun T, et al. High mobility group proteinmediated transcription requires DNA damage marker gamma-H2AX. Cell Res. 2015; 25:837-850.

44. Wu J, Liu Z, Shao C, Gong Y, Hernando E, Lee P, Narita M, Muller W, Liu J, Wei JJ. HMGA2 overexpression-induced ovarian surface epithelial transformation is mediated through regulation of EMT genes. Cancer Res. 2011; 71:349-59.

45. Tan EJ, Kahata K, Idas O, Thuault S, Heldin CH, Moustakas A. The high mobility group A2 protein epigenetically silences the Cdh1 gene during epithelial-to-mesenchymal transition. Nucleic Acids Res. 2015; 43:162-178.

46. Morishita A, Zaidi MR, Mitoro A, Sankarasharma D, Szabolcs M, Okada Y, D'Armiento J, Chada K. HMGA2 Is a Driver of Tumor Metastasis. Cancer Res. 2013; 73:4289-4299.

47. Li Z, Gilbert JA, Zhang Y, Zhang M, Qiu Q, Ramanujan K, Shavlakadze T, Eash JK, Scaramozza A, Goddeeris MM, Kirsch DG, Campbell KP, Brack AS, et al. An HMGA2IGF2BP2 axis regulates myoblast proliferation and myogenesis. Dev Cell. 2012; 23:1176-1188.

48. Li Y, Dai Y, Zhang X, Chen J. Three-layered polyplex as a microRNA targeted delivery system for breast cancer gene therapy. Nanotechnology. 2017; 28:285101.

49. Setua S, Khan S, Yallapu MM, Behrman SW, Sikander M, Khan SS, Jaggi M, Chauhan SC. Restitution of Tumor Suppressor MicroRNA-145 Using Magnetic Nanoformulation for Pancreatic Cancer Therapy. J Gastrointest Surg. 2017; 21:94-105. 